\title{
Bridging the Divide: Integrating Animal and Plant Paradigms to Secure the Future of Biodiversity in Fire-Prone Ecosystems
}

\author{
Luke T. Kelly ${ }^{1, *}$, Lluís Brotons ${ }^{2,3,4} \mathbb{D}^{\mathbb{D}}$, Katherine M. Giljohann ${ }^{5}$, Michael A. McCarthy ${ }^{5} \mathbb{D}^{(}$, \\ Juli G. Pausas ${ }^{6}$ and Annabel L. Smith ${ }^{7}$ (i) \\ 1 School of Ecosystem and Forest Sciences, University of Melbourne, Parkville, VIC 30105, Australia \\ 2 InForest Joint Research Unit (CREAF-CTFC), Crta. de Sant Llorenç de Morunys, Km. 2, 25280 Solsona, Spain; \\ lluis.brotons@gmail.com \\ 3 CREAF, Campus de Bellaterra (UAB) Edifici C 08193 Cerdanyola del Vallès, Spain \\ 4 CSIC, 08193 Cerdanyola del Vallès, Spain \\ 5 School of BioSciences, University of Melbourne, Parkville, VIC 3010, Australia; \\ kmgi@unimelb.edu.au (K.M.G.); mamcca@unimelb.edu.au (M.A.M.) \\ 6 CIDE-CSIC, Ctra. Naquera Km. 4.5, 46113 Montcada, Valencia, Spain; juli.g.pausas@ext.uv.es \\ 7 Department of Zoology, School of Natural Sciences, Trinity College Dublin, Dublin 2, Ireland; \\ annabel@smithecology.org \\ * Correspondence: 1tkelly@unimelb.edu.au
}

Received: 18 July 2018; Accepted: 8 August 2018; Published: 10 August 2018

\begin{abstract}
Conserving animals and plants in fire-prone landscapes requires evidence of how fires affect modified ecosystems. Despite progress on this front, fire ecology is restricted by a dissonance between two dominant paradigms: 'fire mosaics' and 'functional types'. The fire mosaic paradigm focuses on animal responses to fire events and spatial variation, whereas the functional type paradigm focuses on plant responses to recurrent fires and temporal variation. Fire management for biodiversity conservation requires input from each paradigm because animals and plants are interdependent and influenced by spatial and temporal dimensions of fire regimes. We propose that better integration of animal-based and plant-based approaches can be achieved by identifying common metrics that describe changes in multiple taxa; linking multiple components of the fire regime with animal and plant data; understanding plant-animal interactions; and incorporating spatial and temporal characteristics of fires into conservation management. Our vision for a more integrated fire ecology could be implemented via a collaborative and global network of research and monitoring sites, where measures of animals and plants are linked to real-time data on fire regimes.
\end{abstract}

Keywords: biodiversity monitoring; fire ecology; fire management; fire mosaic; functional trait; life-history; plant functional type; plant-animal interactions; pyrodiversity; wildfire

\section{Introduction}

Historical fire regimes have shaped biodiversity, but conserving animals and plants in contemporary landscapes requires evidence of how fires affect ecosystems that are modified by and subject to new threats [1]. Although progress has been made on this front, fire ecology is still restricted by a dissonance between two dominant paradigms that differ in theory and application: 'fire mosaics' and 'functional types' [2]. The fire mosaic paradigm focuses on animal responses to fire events. Fire management under this paradigm typically aims to create spatially diverse fire mosaics to promote biodiversity or the persistence of a small number of focal species [3]. By contrast, the functional type paradigm focuses on plant responses to recurrent fires. Fire management under 
this paradigm is guided by the life-history traits of plants and aims for temporal variation within acceptable fire intervals [4].

Fire management for biodiversity conservation cannot be achieved by applying either paradigm in isolation: it requires input from each because animals and plants are both of value, interdependent, and influenced by the spatial and temporal dimensions of fire regimes. We propose that better integration of animal-based and plant-based approaches can be achieved by identifying common metrics that describe changes in multiple taxa, linking multiple components of the fire regime with measures of animals and plants, understanding shared mechanisms underpinning animal and plant associations with fires, and incorporating spatial and temporal characteristics of fires into conservation management.

\section{Animal and Plant Paradigms in Fire Ecology}

Fire science and management vary greatly between continents and ecosystems but there is value in condensing knowledge of both animals and plants to enhance application of fire ecology. To this end, we identify four general characteristics of animal and plant paradigms and how they differ (Figure 1).

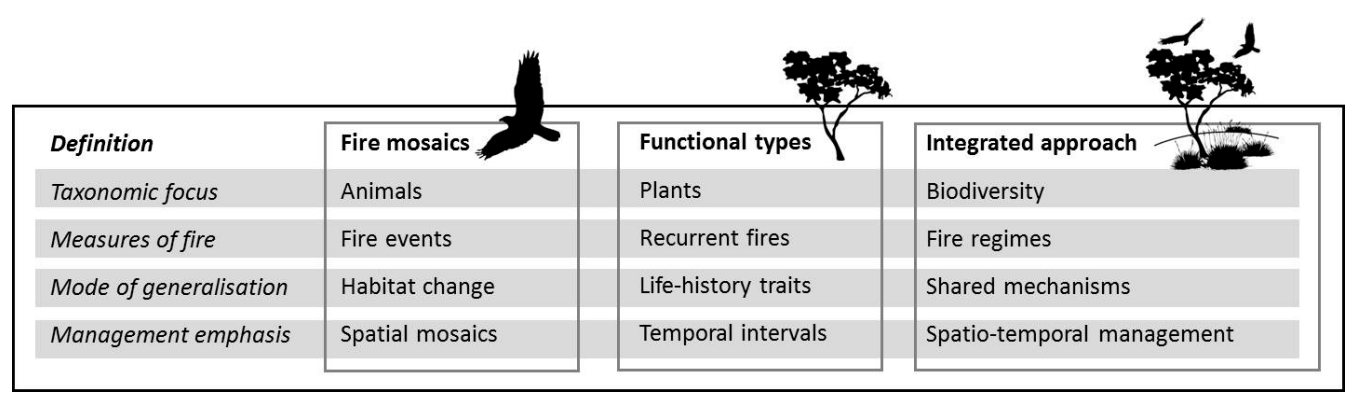

Figure 1. Fire mosaic and functional type paradigms can be defined by the following characteristics: (i) taxonomic focus (animal-based vs. plant-based); (ii) how they characterize fire regimes (fire events vs. recurrent fires); (iii) the mode of generalization (habitat change vs. life-history traits); and (iv) implications for fire management (spatial mosaics vs. temporal intervals). A more integrated approach would emphasize: multiple taxonomic groups and their interactions (biodiversity); different components of the fire regime acting in concert (fire regimes); comprehensive understanding of mechanisms underpinning biotic associations with fire and interdependency between different taxa (shared mechanisms); and decision-making that considers how both spatial and temporal dimensions of fire regimes influence biodiversity (spatio-temporal management).

\subsection{Taxonomic Focus}

The different ecology and evolution of plants and animals in fire-prone ecosystems partly explains the distinct management approaches and underpinning research [5]. Plants are immobile throughout much of their life-cycle and many have endogenous means of reproduction from seedbanks or vegetative buds that promote in situ persistence after a fire [6]. Individual animals are more mobile and some can survive fires by moving to refuges or recolonize from surrounding areas after being extirpated from burnt areas [7]. Some differences in management and research are also likely to stem from the separate developments of the animal and plant sciences. We reviewed the ten most recent papers on fire ecology published in each of five exemplar journals (Biological Conservation, Ecology, Forest Ecology and Management, Global Ecology and Biogeography and International Journal of Wildland Fire; $\mathrm{n}=50$ papers) and found that $78 \%$ were solely animal-based or plant-based, and only $22 \%$ investigated both animal and plant associations with fire [Supplementary Material]. This suggests research culture and training play a part in forming different perspectives. 


\subsection{Measures of Fire}

A central concept in fire ecology is the fire regime, which describes the repeated pattern of fires in a given area and their characteristics [8,9]. For animals, commonly measured components of the fire regime include those representing fire events, including severity and patchiness, and time since the last fire [2]. These components can affect animals' capacity to survive fire and their subsequent ability to find food, find shelter, and recolonize regenerating habitats. For plants, fire frequency and the interval between successive fires have been of central importance to research [10]. The time between fires sets the window for growth and reproduction in many plants. Studies of animals and plants that explore combinations of fire regime characteristics are increasing [11] and represent an important development in fire ecology.

\subsection{Mode of Generalization}

Generalization assists both ecological understanding and prediction across taxa, times, and places. Theories of post-fire succession underpin much animal research in fire ecology. For example, the 'habitat accommodation model' (Fox 1982) predicts that faunal species enter the post-fire succession when vegetation structure and floristic resources becomes suitable for them. As the vegetation changes and becomes less suitable for a species, it will be excluded from the succession or decline in abundance from competition [12]. In search of unifying trends, fire response patterns have been linked to animal life-history, including shelter, food, fecundity, and mobility; such approaches have provided informative descriptions but have often met with little predictive success [13].

Life-history approaches have been widely used for generalization in plant ecology [6]. For example, Noble and Slatyer (1980) derived an important method for predicting plant dynamics in relation to recurrent fires using three groups of traits or 'vital attributes': method of arrival or persistence at a site during and after fire, the ability to establish and grow to maturity, and time taken to reach critical life stages [14]. Grouping plants into functional types, i.e., sets of species that share traits, has been used repeatedly to examine post-fire responses of plants with considerable predictive success $[6,15]$.

\subsection{Management Emphasis}

A focus on fire events, vegetation succession, and accompanying changes in habitat structure has translated into management for animals that aims for spatially diverse fire mosaics [2]. A widespread expectation is that 'pyrodiversity promotes biodiversity', which is a prediction based on linking the persistence of individual species, and the coexistence of multiple species, to variation in the composition and configuration of fire mosaics [3]. This perspective highlights threats to animal conservation triggered by large, severe, and uniform fires, which, in some locations, have been linked to a build-up of fuels under fire suppression. Management to achieve spatially diverse fire regimes varies between continents and ecosystems. In Australia, South Africa, and increasingly in Europe and South America, patch-mosaic burning or planned burning have been implemented [3,6]. In North America, there has been a strong focus on restoration of fire regimes to historical conditions $[1,16]$, and, more recently, on encouraging natural patterns of ignitions that result in mixed-severity fires [17]. The fire mosaic paradigm and pyrodiversity hypothesis have been criticized for their simplistic representation of fire regimes and animal habitat [2,3].

An emphasis on functional types has translated into management for plants that aims for variation in fire intervals over time. An influential approach uses plant life-history traits, such as time to reproductive maturity, life-spans of established plants, and seed longevity to determine minimum and maximum fire intervals, beyond which a significant decline of species populations is predicted [8]. Accordingly, domains of tolerable fire intervals are derived and used to guide vegetation management [4]. This perspective highlights two main threats: immaturity risk, where fire intervals are shorter than the time needed for plants to mature and accumulate seed; and senescence risk, where fire 
intervals are longer than seed and plant life-spans [6]. Plant life-history and demographic data have been used widely to guide fire management in Australia [4] and South Africa [18], with examples from other locations, such as North America [19], growing. Useful approaches have also been developed that consider multiple measures of fire regimes-'thresholds of particular concern' and 'bounded ranges of variation' [16] — but in practice are rarely linked to requirements of plants.

\section{Towards a More Integrated Fire Ecology}

We propose practical ways to achieve better integration of animal and plant perspectives in fire ecology and management (Figure 1: Integrated approach). Our aim is to identify a small set of opportunities to advance fire ecology and management regardless of the focal ecosystem or taxa.

\subsection{Common Measures of Biodiversity}

A simple way to enhance management and learning is to directly measure plants, animals, and habitat elements. While some measures of biodiversity will be context specific, recording observations in a standardized way to allow comparisons between taxa and ecosystems is valuable. Harmonization of global biodiversity monitoring using Essential Biodiversity Variables (EBVs) [20] could be adapted to fire-prone ecosystems. Under the EBVs framework, six dimensions of biodiversity have been identified-including genetic composition, species population, species traits, community composition, ecosystem function, and ecosystem structure-to assess biodiversity change [20]. As a first step, essential variables used to inform knowledge of species persistence in fire-prone landscapes could include the occurrence and abundance of animals and plants at key life stages [13], traits that mediate fire responses at different levels of ecological organization [15], and elements of habitat structure, such as tree size and density [17]. Systematic measures of species occurrence or abundance could be pooled to provide multi-species indicators of biodiversity, and models used to extrapolate observations from sites to landscapes. Monitoring multiple species and taxa will help to avoid some of the pitfalls of single-species management, such as when a focal or indicator species is incorrectly assumed to represent biodiversity more broadly [1]. An ongoing challenge is the complexity in measuring multiple taxonomic groups, from invertebrates and herbs to larger vertebrates and trees, which show great variation in size, diversity, and detectability.

\subsection{Multiple Components of Fire Regimes}

Rapid progress in satellite remote sensing and aerial photography has already produced valuable resources that aid choices about when and where to conduct fuel management and fire suppression [2]. One practical challenge is describing variation in fire regimes over space and time in a consistent way so that studies can be compared at different times and places. Several metrics of pyrodiveristy have been developed, and the synthesis and testing of these approaches would facilitate advances globally. Another challenge is the coupling of growing spatial data on fire with the sampling of animals and plants. New work on spatially explicit power analysis shows how the location and level of sampling required to detect changes in animal and plant populations can be identified [21]. In combination with common measures of plants, animals, and fire regimes, power analysis could be used to design the assessment and monitoring of fire management and boost the understanding of multiple components of fire regimes.

\subsection{Shared Mechanisms}

Approaches for generalization in animal and plant ecology usually concentrate on resource change (e.g., food, light) or traits, but rarely both. One way to formally bridge resource change and trait-based approaches is to incorporate functional traits into models of species-fire relationships. For example, Thomas and Vesk (2017) built a hierarchical multi-species model to predict tree species growth trajectories at different times since fire as a function of their traits (stem density, seed size, and specific leaf area) [22]. This approach could be extended to animal data, and can be combined 
with new measures of ecological, behavioral, and physiological traits [5], to provide a mechanistic understanding of animal succession and better integration with plant functional trait frameworks.

Fire not only affects animals and plants but also their interactions. Interactions such as pollination and seed dispersal play an essential role in the maintenance of biodiversity, and explicit consideration of plant-animal interactions will provide new insights and benefit fire management and conservation (Table 1). In addition to revealing shared mechanisms, a focus on interactions between trophic levels will help to understand the evolution of life-history strategies and traits in fire-prone ecosystems. For example, Talluto and Benkman (2014) showed that the frequency of serotiny in lodgepole pine across Yellowstone National Park reflects selection pressure from fire and seed predation by the red squirrel [23]. This highlights that ecosystem structure and function vary as a result of spatial and temporal variation in fires and plant-animal interactions.

Table 1. Consideration of both animals and plants provides new insights and benefits fire management for biodiversity conservation.

\begin{tabular}{|c|c|}
\hline Process & $\begin{array}{l}\text { Benefit to Ecological Understanding and Fire } \\
\text { Management }\end{array}$ \\
\hline Habitat development & $\begin{array}{l}\text { Considering structural changes of plants provided new } \\
\text { understanding of habitat provision over century-long time } \\
\text { scales and showed that tolerable fire intervals based solely } \\
\text { on plant occurrence were too short for animal conservation } \\
(\text { Haslem et al. 2011)*. }\end{array}$ \\
\hline Pollination & $\begin{array}{l}\text { Nest location and floral resource use mediate pollinator } \\
\text { responses to fire. Plant traits such as growth form, } \\
\text { phenology and bud location influence flowering responses } \\
\text { to fire. Pollinators most vulnerable to changing fire regimes } \\
\text { are predicted to be those that nest above-ground and have } \\
\text { one brood per year (Brown et al. 2017). }\end{array}$ \\
\hline Decomposition & $\begin{array}{l}\text { Fossorial mammals affected fire behavior via an increase in } \\
\text { the rate of organic matter breakdown. Reintroducing } \\
\text { fossorial mammal species to landscapes where they have } \\
\text { previously been extinct offers a new way to modify fire } \\
\text { regimes for the benefit of plant and animal conservation } \\
\text { (Hayward et al. 2016). }\end{array}$ \\
\hline Seed dispersal & $\begin{array}{l}\text { Colonization of holm oak in burnt forest is mediated by } \\
\text { acorn dispersal by Eurasian jays. Post-fire salvage logging } \\
\text { reduced the strength of this key plant-animal interaction. } \\
\text { Management policies of non-intervention after forest fire are } \\
\text { likely to increase the resilience of the ecosystem (Castro et al. } \\
\text { 2012). }\end{array}$ \\
\hline Seed predation & $\begin{array}{l}\text { Mediterranean gorse seeds are predated upon by the weevil } \\
\text { Exapion fasciolatum. Mediterranean gorse experienced lower } \\
\text { seed damage in burnt compared to unburnt areas. Plants can } \\
\text { benefit from fire through disruption of antagonistic } \\
\text { interactions with seed predators and this might be one } \\
\text { mechanism promoting success of fire-adapted plants (García } \\
\text { et al. 2016). }\end{array}$ \\
\hline Grazing & $\begin{array}{l}\text { In periods of low rainfall, grazing by kangaroos and feral } \\
\text { herbivores following prescribed fire had a large effect on the } \\
\text { survival of seedlings and resprouting plants. This indicates } \\
\text { that conservation of plants and animals will benefit from fire } \\
\text { management that considers how herbivore management } \\
\text { influences a foundation species of semi-arid Australia } \\
\text { (Giljohann et al. 2017). }\end{array}$ \\
\hline Community assembly & $\begin{array}{l}\text { Spatial and temporal variation in fires influences community } \\
\text { assembly globally (Kelly \& Brotons 2017), and feedback } \\
\text { among fires, biodiversity and ecological processes are } \\
\text { central to understanding community-level changes } \\
\text { (Bowman et al. 2016). For example, fire in combination with } \\
\text { experimental exclusion of seed-eating rodents shifted a } \\
\text { desert shrubland to a low-diversity, invasive grassland. In } \\
\text { areas where they remained, rodents created biotic resistance } \\
\text { to invasive plants, with cascading effects on plant diversity } \\
\text { (St. Clair et al. 2016). }\end{array}$ \\
\hline
\end{tabular}

* Additional references in Table 1: Haslem, A. et al. J. Appl. Ecol. 2011, 48, 247-256; Brown, J. et al. J. Appl. Ecol. 2017, 54, 313-322; Hayward, M.W. et al. Anim. Conserv. 2016, 19, 490-497; Castro, J. et al. Ecosphere 2012, 3, 1-12; García, Y. et al. Oecologia, 2016, 182, 1165-1173; Giljohann, K.M. J. Ecol. 2017, 105, 1562-1570; Kelly, L.T. and Brotons, L. Science, 2017, 355, 1264-1265; Bowman, D.M.J.S. et al. Phil. Trans. R. Soc. B. 2016, 371, 20150169; St. Clair, S.B. et al. Ecology 2016, 97, 1700-1711. 


\subsection{Spatio-Temporal Fire Management}

There is broad agreement that spatial and temporal dimensions of fire regimes matter but it is rare that interconnections between the two are explicitly incorporated into management for biodiversity. One reason is that data on plants, animals, and spatio-temporal mosaics has been lacking [11]. In part, this is being addressed by a surge of new studies on fire regimes and biodiversity [3]. A continuing issue is that results of studies are rarely available as mapped outputs that can directly inform spatial-temporal management. To complement maps of fire history, we recommend mapping outputs from models that directly link biodiversity with measures of fires (e.g., species distribution and population models) [24]. This would facilitate comparisons of fire impacts across different taxa and in different places, help to identify when and where key populations of plants and animals will be located, and strengthen efforts to define management thresholds in different components of fire regimes. We are already using linked fire and biodiversity data to inform decision making across large areas of southern Australia and northern Spain $([3,25]$ and references therein). Useful extensions could include mapping interactions and interdependencies between plants and animals, such as pollinator networks (Table 1); linking spatial models to fire simulations and management strategies to predict future changes in plant and animal populations; and producing real-time environmental data to aid the urgent decisions that affect people and biodiversity during fire events.

We have only touched on some important debates that span animal and plant ecology such as single- vs. multi-species management, historical range and variability vs. contemporary fire management, and correlative vs. mechanistic approaches. Insights from these other approaches are likely to produce ideas additional to those proposed in this paper.

\section{Conclusions}

Many animals and plants show different responses to fires but we argue that searching for commonality and links will enhance learning about both groups. Our vision for a more integrated fire ecology could be implemented via a collaborative and global network of research and monitoring sites in fire-prone ecosystems, where measures of animals and plants are linked to real-time data on the spatial and temporal dimensions of fires. Well-designed monitoring would provide the following: opportunities to reveal new ecological patterns, processes, and interactions between animals and plants; a more robust understanding of the effect of fire regimes on biodiversity; and a strong basis for choosing between alternative fire management strategies. This proposal would be strengthened by collaborations between animal and plant ecologists, using emerging approaches for generalization such as trait-based models. Finally, bringing together animal and plant perspectives will benefit from other recent developments in fire ecology, notably, frameworks that recognize the importance of socio-ecological linkages, adaptive resilience, and decision making under uncertainty [3,16].

Supplementary Materials: The following are available online at http:/ /www.mdpi.com/2571-6255/1/2/29/s1.

Author Contributions: L.K. conceived the idea for the paper and led the writing. All authors made substantial contributions to the development of ideas and drafts.

Funding: Kelly was funded by the Australian Research Council Centre of Excellence for Environmental Decisions and a Victorian Postdoctoral Research Fellowship delivered by veski on behalf of the Victorian Government. Brotons and Pausas were funded by the Government of Spain on Project CGL2017-89999-C2 and CGL2015-64086-P, respectively. Smith was supported by Marie Skłodowska-Curie Individual Fellowship FIRESCAPE-746191 under the EU H2020 Programme for Research and Innovation.

Acknowledgments: Many thanks to Clare Kelly who co-designed Figure 1 and Table 1. We appreciate the useful comments and suggestions provided by the reviewers of this paper.

Conflicts of Interest: The authors declare no conflict of interest. 


\section{References}

1. Freeman, J.; Kobziar, L.; Rose, E.W.; Cropper, W. A critical evaluation of the historical fire regime concept in conservation. Conserv. Biol. 2017, 31, 976-985. [CrossRef] [PubMed]

2. Bradstock, R.A.; Williams, R.J.; Gill, A.M. Future fire regimes of Australian ecosystems: new perspectives on enduring questions of management. In Flammable Australia: Fire Regimes, Biodiversity and Ecosystems in a Changing World; Bradstock, R.A., Gill, A.M., Williams, R.J., Eds.; CSIRO Publishing: Collingwood, Australia, 2012; pp. 307-324. ISBN 9780643104846.

3. Kelly, L.T.; Brotons, L.; McCarthy, M.A. Putting pyrodiversity to work for animal conservation. Conserv. Biol. 2017, 31, 952-955. [CrossRef] [PubMed]

4. Shedley, E.; Burrows, N.; Yates, C.J.; Coates, D.J. Using bioregional variation in fire history and fire response attributes as a basis for managing threatened flora in a fire-prone Mediterranean climate biodiversity hotspot. Aust. J. Bot. 2018, 66, 134-143. [CrossRef]

5. Pausas, J.G.; Parr, C.L. Towards an understanding of the evolutionary role of fire in animals. Evol. Ecol. 2018, 1-13. [CrossRef]

6. Keeley, J.E.; Bond, W.J.; Bradstock, R.A.; Pausas, J.G.; Rundel, P.W. Fire in Mediterranean Ecosystems: Ecology, Evolution and Management; Cambridge University Press: Cambridge, UK, 2012; ISBN 9780521824910.

7. Puig-Gironès, R.; Clavero, M.; Pons, P. Importance of internal refuges and the external unburnt area in the recovery of rodent populations after wildfire. Int. J. Wildl. Fire 2018, 27, 425-436. [CrossRef]

8. Gill, A.M.; McCarthy, M.A. Intervals between prescribed fires in Australia: What intrinsic variation should apply? Biol. Conserv. 1998, 85, 161-169. [CrossRef]

9. Baker, W.L. Fire Ecology in Rocky Mountain Landscapes; Island Press: Washington, DC, USA, 2009; ISBN 9781597261821.

10. Bond, W.J.; van Wilgen, B.W. Fire and Plants; Chapman and Hall: London, UK, 1996; ISBN 9789400914995.

11. Foster, C.N.; Barton, P.S.; Robinson, N.M.; MacGregor, C.I.; Lindenmayer, D.B. Effects of a large wildfire on vegetation structure in a variable fire mosaic. Ecol. Appl. 2017, 27, 2369-2381. [CrossRef] [PubMed]

12. Fox, B.J. Fire and mammalian secondary succession in an Australian coastal heath. Ecology 1982, 63, 1332-1341. [CrossRef]

13. Smith, A.L. Successional changes in trophic interactions support a mechanistic model of post-fire population dynamics. Oecologia 2018, 186, 129-139. [CrossRef] [PubMed]

14. Noble, I.R.; Slatyer, R.O. The use of vital attributes to predict successional changes in plant communities subject to recurrent disturbances. Vegetatio 1980, 43, 5-21. [CrossRef]

15. Keith, D.A. Functional traits: their roles in understanding and predicting biotic responses to fire regimes from individuals to landscapes. In Flammable Australia: Fire Regimes, Biodiversity and Ecosystems in a Changing World; Bradstock, R.A., Gill, A.M., Williams, R.J., Eds.; CSIRO Publishing: Collingwood, Australia, 2012; pp. 97-125. ISBN 9780643104846.

16. Moritz, M.A.; Hurteau, M.D.; Suding, K.N.; D'Antonio, C.M. Bounded ranges of variation as a framework for future conservation and fire management. Ann. N. Y. Acad. Sci. 2013, 1286, 92-107. [CrossRef] [PubMed]

17. Hessburg, P.F.; Spies, T.A.; Perry, D.A.; Skinner, C.N.; Taylor, A.H.; Brown, P.M.; Stephens, S.L.; Larson, A.J.; Churchill, D.J.; Povak, N.A.; et al. Tamm review: management of mixed-severity fire regime forests in Oregon, Washington, and Northern California. For. Ecol. Manag. 2016, 366, 221-250. [CrossRef]

18. Kraaij, T.; Cowling, R.M.; van Wilgen, B.W.; Schutte-Vlok, A. Proteaceae juvenile periods and post-fire recruitment as indicators of minimum fire return interval in eastern coastal fynbos. Appl. Veg. Sci. 2013, 16, 84-94. [CrossRef]

19. Menges, E.S. Integrating demography and fire management: An example from Florida scrub. Aust. J. Bot. 2007, 55, 261-272. [CrossRef]

20. Pereira, H.M.; Ferrier, S.; Walters, M.; Geller, G.N.; Jongman, R.H.G.; Scholes, R.J.; Bruford, M.W.; Brummitt, N.; Butchart, S.H.M.; Cardoso, A.C.; et al. Essential biodiversity variables. Science 2013, 339, 277-278. [CrossRef] [PubMed] 
21. Einoder, L.D.; Southwell, D.M.; Gillespie, G.R.; Monfort, J.J.L.; Wintle, B.A. Optimising broad-scale monitoring for trend detection: review and re-design of a long-term program in northern Australia. In Monitoring Threatened Species and Ecological Communities; Legge, S., Lindenmayer, D., Robinson, N., Scheele, B., Southwell, D., Wintle, B., Eds.; CSIRO Publishing: Collingwood, Australia, 2018; pp. 271-280. ISBN 9781486307715.

22. Thomas, F.M.; Vesk, P.A. Growth races in the Mallee: Height growth in woody plants examined with a trait-based model. Austral Ecol. 2017, 42, 790-800. [CrossRef]

23. Talluto, M.V.; Benkman, C.W. Conflicting selection from fire and seed predation drives fine-scaled phenotypic variation in a widespread North American conifer. Proc. Natl. Acad. Sci. USA 2014, 111, 9543-9548. [CrossRef] [PubMed]

24. Franklin, J.; Regan, H.M.; Syphard, A.D. Linking spatially explicit species distribution and population models to plan for the persistence of plant species under global change. Environ. Conserv. 2013, 41, 97-109. [CrossRef]

25. Brotons, L.; De Cáceres, M.; Fall, A.; Fortin, M.J. Modeling bird species distribution change in fire prone Mediterranean landscapes: incorporating species dispersal and landscape dynamics. Ecography 2012, 35, 458-467. [CrossRef]

(C) 2018 by the authors. Licensee MDPI, Basel, Switzerland. This article is an open access article distributed under the terms and conditions of the Creative Commons Attribution (CC BY) license (http:/ / creativecommons.org/licenses/by/4.0/). 